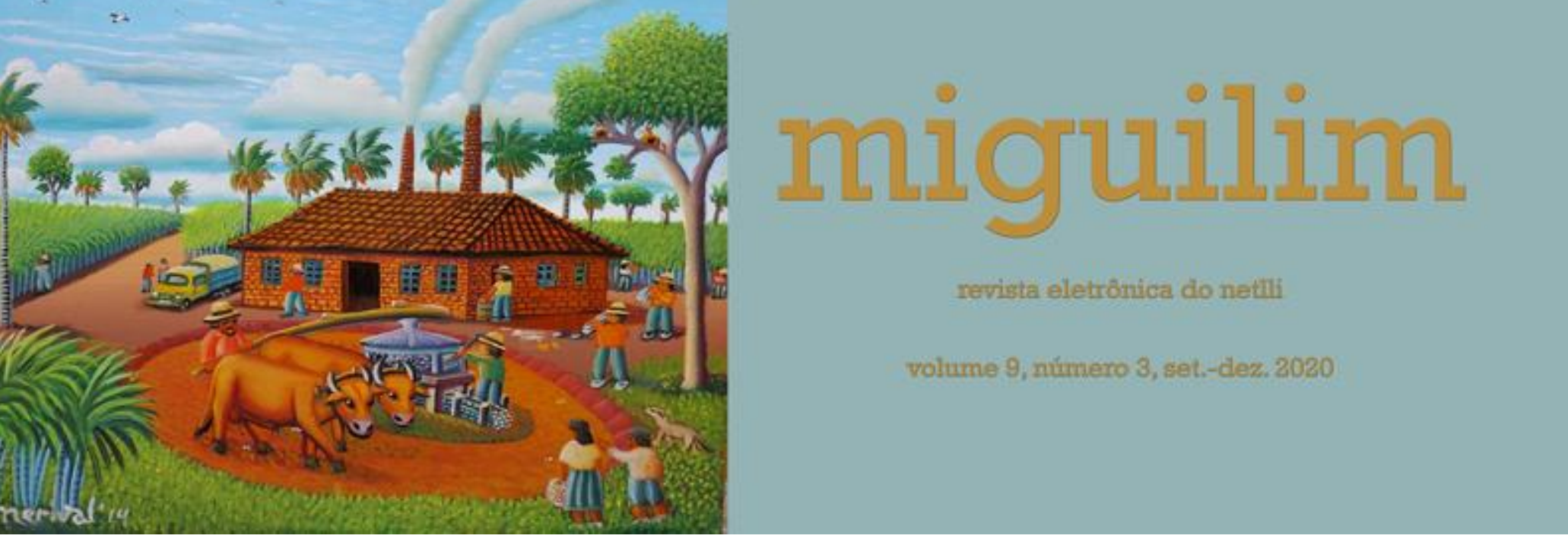

\title{
HISTÓRIAS DO PAÍS DE ALI-BABÁ, DE DEIFILIA, RACHEL E AURORA: UM BREVE ESTUDO SISTEMATIZADO
}

\author{
HISTÓRIAS DO PAÍS DE ALI-BABÁ, DE DEIFILIA, \\ RACHEL E AURORA: A BRIEF SYSTEMATIC STUDY
}

\author{
Cristina Rothier DUARTE \\ Universidade Federal da Paraíba, Brasil
}

\author{
RESUMO | INDEXAÇÃO | TEXTO | REFERÊNCIAS | CITAR ESTE ARTIGO | A AUTORA \\ RECEBIDO EM 22/06/2020 APROVADO EM 08/10/2020 \\ DOI: https://doi.org/10.47295/mgren.v9i3.2488
}

Resumo

Neste artigo, realizamos um breve estudo de uns dos últimos volumes da Biblioteca Infantil da Livraria Quaresma, a obra Histórias do País de Ali-Babá, das autoras Deifilia da Silva Quaresma, Rachel da Silva Quaresma e Aurora da Silva Quaresma. Este trabalho se justifica pela falta de visibilidade que a obra tem dentro da historiografia da Literatura Infantil brasileira, embora faça parte da coleção de inaugurou uma literatura mais próxima cultural e linguisticamente da criança brasileira. Portanto, apresentamos como objetivos específicos a sistematização da obra e o estudo das narrativas "A chinelinha de ouro" e "Castigo de um anjo", a partir da classificação dos contos populares encetados por Coelho (2000) e Cascudo (1952). A metodologia empregada foi a pesquisa bibliográfica de cunho qualitativo. Como resultado, percebemos que a obra segue as características predominantes da Literatura infantil da época, uma literatura que, apesar de visar ao prazer do leitor, é dotada de um forte caráter exemplar e moralizante. 


\section{Abstract}

In this article, we carried out a brief study of one of the last volumes of the Biblioteca Infantil of Livraria Quaresma, the work Histórias do País de Ali-Babá, by the authors Deifilia da Silva Quaresma, Rachel da Silva Quaresma and Aurora da Silva Quaresma. This work is justified by the lack of visibility that the work has within the historiography of Brazilian Children's Literature, although part of the collection that inaugurated a literature that is closer culturally and linguistically to the Brazilian child. Therefore, we present as specific objectives the systematization of the work and the study of the narratives "A chinelinha de ouro" and "Castigo de um anjo", based on the classification of popular tales started by Coelho (2000) and Cascudo (1952). The methodology used was a qualitative bibliographic research. As a result, we realize that the work follows the predominant characteristics of children's Literature of the time, a literature endowed with a strong exemplary and moralizing character, despite seeking the pleasure of the reader.

\section{Entradlas para indexação}

PALAVRAS-CHAVE: Literatura infantil brasileira. Biblioteca Infantil da Livraria Quaresma. Histórias do País de Ali-Babá.

KEYWORDS: Brazilian children's literature. Biblioteca Infantil of Livraria Quaresma. Histórias do País de Ali-Babá.

\section{Texto integral}

A Literatura Infantil brasileira dotada de cores nacionais surgiu no final do século XIX com as produções da Livraria Quaresma. Antes disso, o que tínhamos eram livros estrangeiros, em francês ou em português lusitano, o que dificultava a compreensão das crianças brasileiras. Vendo, então, um mercado promissor somado a necessidade de se educar os pequenos brasileiros nos moldes da ideologia nacionalista vigente, Pedro da Silva Quaresma, inaugurou a Biblioteca Infantil, sob a organização de Alberto Figueiredo Pimentel. ${ }^{1}$

Uma das últimas obras da coleção, que conta com 12 volumes, é Histórias do País de Ali-Babá, das autoras Deifilia da Silva Quaresma, Rachel da Silva Quaresma e Aurora da Silva Quaresma. Embora esse volume tenha sido publicado cerca de 20 a 30 anos após Contos da Carochinha (1894), ele ainda apresenta as mesmas características que são manifestadas nas demais obras de coleção do gênero conto, quais sejam: narrativas de origem popular com fundo edificante, mas que também servem ao deleite. Porém, diferentemente de Contos da Carochinha, Histórias da Avozinha e Histórias da Baratinha, Histórias do País de Ali-Babá não teve grande repercussão e não mais é publicada nos dias de hoje. Assim, este trabalho se justifica pelo mister de conferir visibilidade à obra Histórias do País de Ali-Babá devido à sua importância enquanto título que constitui a primeira coleção de livros brasileiros destinada às nossas crianças. 
Como objetivos específicos, visamos à sistematização da obra, apresentando a sua composição, e ao estudo de 2 dos seus 20 contos: "A chinelinha de ouro" e "Castigo de um anjo". Tal escolha se deu em razão de essas narrativas pertencerem aos tipos de contos predominantes na obra: o conto maravilhoso ou de encantamento; e a parábola ou conto religioso. Para tanto, utilizamos como aporte teórico os estudos de Nelly Novaes Coelho (2000) e Câmara Cascudo (1952). Metodologicamente, empregamos a pesquisa bibliográfica de cunho qualitativo.

0 trabalho foi organizado em duas seções principais: i. Era uma vez as Histórias do País de Ali-Babá, em que tratamos do contexto da obra dentro da coleção Biblioteca Infantil da Livraria Quaresma; ii. Um breve estudo sistematizado de Histórias do País de Ali-Babá, em que trazemos a estrutura da obra, a classificação dos contos, e, por fim, a sinopse e um breve estudo de duas narrativas, "A chinelinha de ouro" e "Castigo de um anjo".

\section{ERA UMA VEZ AS HISTÓRIAS DO PAÍS DE ALI-BABÁ}

A literatura infantil, no século XIX, conforme trouxemos na introdução deste trabalho, era apresentada às crianças brasileiras em língua estrangeira e, quando traduzida para o português lusitano, era dotada de um vocabulário e de expressões distantes, cultural e linguisticamente, de nossas crianças. Dessa forma, a necessidade de narrativas que não provocassem estranhamento e dificuldade para a compreensão era premente, visto que havia o desejo de letrar os brasileiros do futuro.

Fazendo parte desse contexto, o mercado livreiro do Brasil iniciava a todo vapor, e, acompanhando esse ritmo, Pedro da Silva Quaresma, proprietário da Livraria Quaresma, antiga Livraria do Povo, idealizou uma literatura infantil dotada de simplicidade, bem próxima das histórias das amas de leite e abrasileiradas, de modo que fizesse o gosto infantil. Com efeito, convidou para a organização de seu projeto Alberto Figueiredo Pimentel, jornalista e escritor naturalista conhecido por uma escrita picante, considerada pelos seus pares como pornográfica e inapropriada para mulheres.

Incumbido, então, de realizar o que Quaresma engendrou, o afamado escritor iniciou a composição da Biblioteca Infantil da Livraria Quaresma, em 1894, com a publicação de Contos da Carochinha, cuja primeira edição reunia 40 contos populares, morais e proveitosos, com uma linguagem, agora, mais facilitada e provida de um abrasileiramento, ainda não visto, a fim de atender à demanda.

Esse livro foi seguido por mais 11 volumes de gêneros variados: contos, textos dramáticos, poesias, cantigas, brincadeiras, enfim, toda uma espécie de produção que vinha para, além de educar e de propagar comportamentos desejados para uma criança daquela época, divertir, entreter e deleitar. 0 sucesso de Contos da Carochinha foi imediato. Bem recebida pelos pequenos leitores, a obra esgotou-se logo que fora lançada, de maneira que, naquele mesmo ano, houve mais duas edições. Além desse livro, Figueiredo Pimentel publicou mais 5 títulos da 
coleção: Histórias da Avozinha (1896), Histórias da Baratinha (1896), Os Meus Brinquedos (1896), Teatrinho Infantil (1896) e Álbum das Crianças (1897). ${ }^{2}$

Embora tais obras, incluindo Histórias do Arco da Velha (1896), de Annibal Mascarenhas (sob o pseudônimo Viriato Padilha), tinham sido editas e publicadas com curto intervalo de uma em relação à outra, os demais livros que fazem parte da Biblioteca Infantil foram lançados alguns anos depois: $O$ reino das Maravilhas, Contos do País das Fadas, de Gondim da Fonseca, em 1926 e 1932, respectivamente; Histórias Brasileiras e A Árvore de Natal, de Annibal Mascarenhas, assinando como Tycho Brahe, em 1938 e 1939, respectivamente; por fim Histórias do País de Ali-Babá (193-?), de Deifilia, Rachel e Aurora, ainda nos idos dos novecentos, sem sabermos precisar a data.

Outro fato importante a se observar sobre a Biblioteca Infantil da Livraria Quaresma é a permanência da coleção completa, ou seja, já com seus 12 volumes. Temos notícias de que, na década de 50 do século passado, a Biblioteca ainda era comercializada. Contudo, hoje, no mercado, somente podemos encontrar alguns volumes em sebos, porém Contos da Carochinha, Histórias da Baratinha e Histórias da Avozinha, ainda são editadas pela Editora Itatiaia, inclusive esta última está disponível em e-book em duas editoras distintas (Obliq e Alberto Figueiredo Pimentel).

Imagem 1- Capas de livros físicos de edições recentes

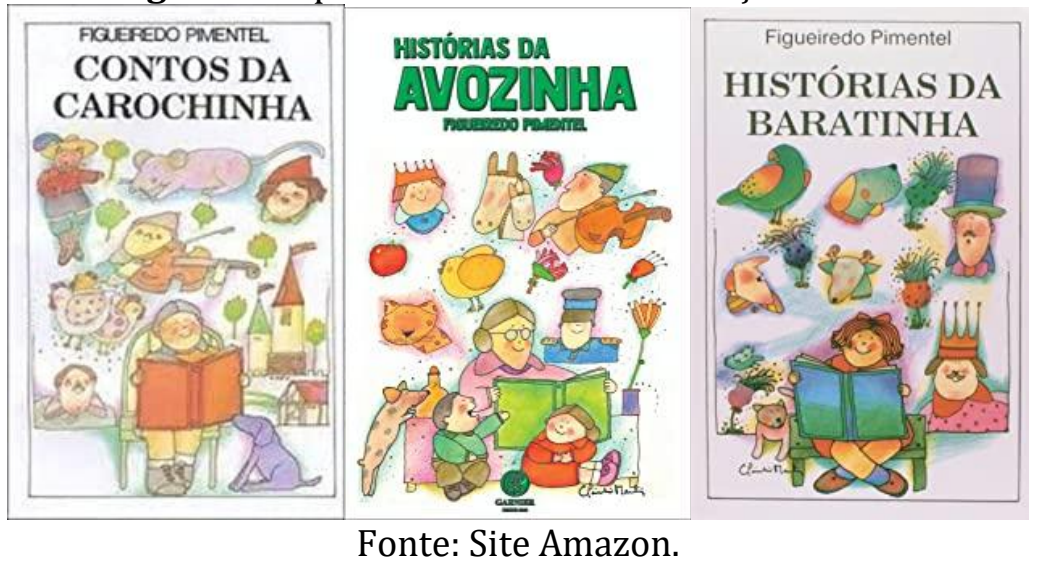

Imagem 2- Capas de e-books 


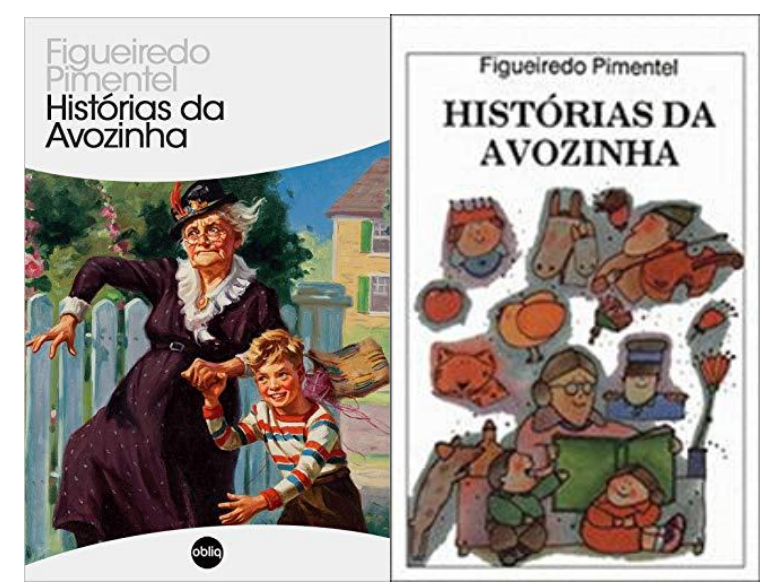

Fonte: Site Amazon.

Entre as obras da Biblioteca Infantil que ainda são encontradas somente em sebos, está Histórias do País de Ali-Babá, de Deifilia, Rachel e Aurora, objeto deste estudo. Importante notar que a obra é dotada de características que destoam da certa uniformidade que há entre as demais obras da coleção: é a única de autoria feminina; tem mais de um autor, a obra não apresenta o nome completo das escritoras e, ainda, ao contrário dos demais escritos que assinam outros livros que não os da Biblioteca, não localizamos outras obras dessas autoras.

$\mathrm{Na}$ intenção de identificá-las, procedemos com algumas buscas em sítios da internet especializados em catalogação de pesquisas (Biblioteca digital de Teses e Dissertações da USP e Catálogo de Teses e Dissertações CAPES), além da plataforma Google Scholar, a fim de localizarmos pesquisas que tratassem da vida e obra das autoras. Nessa empreitada, encontramos apenas duas pesquisas (SOUZA, 2017; MEDEIROS, 2010), em que Deifilia, Rachel e Aurora têm mencionados somente os seus prenomes, tais como estão na folha de rosto da obra Histórias do País de Ali-Babá.

Não satisfeitos com tal anonimato, partimos para buscas junto aos periódicos do arquivo digital da Hemeroteca Digital Brasileira, onde localizamos como participantes concorrentes listadas no resultado do concurso no 752 , do semanário das crianças Tico-tico, edição de 26 de março de 1913, Deifilia da Silva Quaresma e Aurora da Silva Quaresma. Rachel da Silva Quaresma foi encontrada na edição de 27 de julho de 1910, do mesmo semanário, também como participante concorrente de um concurso, o no 474.

Por fim, localizamos uma fotografia, publicada no Jornal das moças, edição de abril de 1916, cujo rodapé indica: "As graciosas Rachel, Deifilia e Aurora, filhas do negociante Sr. Pedro da Silva Quaresma." Tais indícios nos levam a crer que as autoras de Histórias do País de Ali-Babá são filhas do proprietário da Livraria Quaresma, Pedro da Silva Quaresma, herdeiras do sobrenome "da Silva Quaresma", portanto: Deifilia da Silva Quaresma, Rachel da Silva Quaresma e Aurora da Silva Quaresma.

Imagem 3 - Fotografia das filhas de Pedro Quaresma 


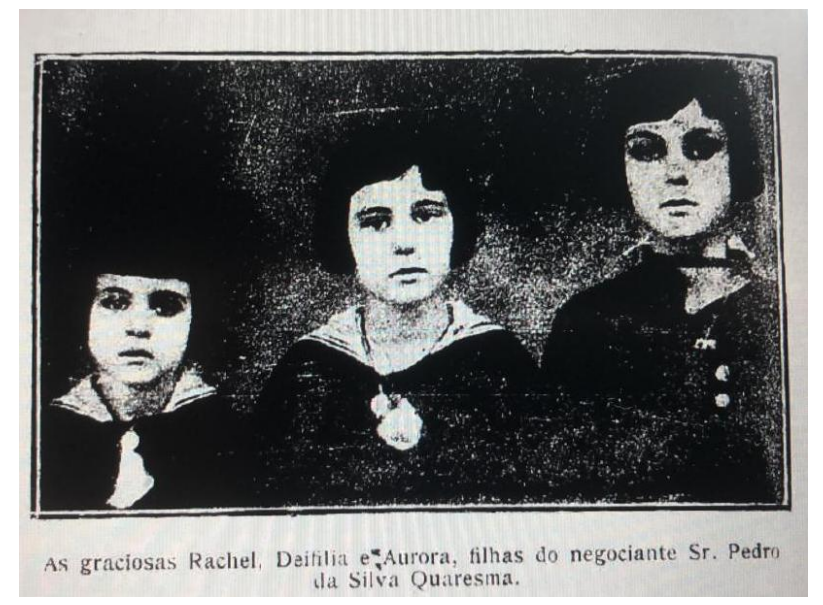

Fonte: Hemeroteca Digital Brasileira.

Uma vez identificadas as autoras de Histórias do País de Ali-Babá, não encontramos nenhuma outra produção por elas assinada, seja individualmente ou em parceria. Desse modo, acreditamos ser essa a única produção literária das escritoras.

Introduzido o contexto de surgimento da obra e devidamente identificadas as autoras, na próxima seção, sistematizamo-la, descrevendo sua composição e tratando brevemente de duas das narrativas reunidas em Histórias do País de AliBabá, para uma compreensão geral e, neste estudo, ainda preliminar acerca desse objeto.

\section{2 $B A B A ́$ \\ UM BREVE ESTUDO SISTEMATIZADO DE HISTÓRIAS DO PAÍS DE ALI-}

Como expusemos anteriormente, não sabemos indicar com exatidão o ano de publicação da obra, porém acreditamos que tenha se dado entre o final da década de 30 e início dos anos 40 dos novecentos. Apesar de ser uma das últimas obras da coleção, o caráter edificante ainda se fazia presente, conforme podemos observar do seu prefácio:

Percorrem-se páginas a seguir e ver-se-á que todos os contos, histórias, de Histórias do País de Ali-Babá - são como verdadeiros apólogos, legítimas parábolas, com um fim altamente moral, digno, virtuoso, narrados sob a forma de atraentes histórias de fadas, de bichos, de lobisomens. (QUARESMA; QUARESMA; QUARESMA, 1958, n. p.).

Todavia não abandona o deleite que os escritos da coleção visavam a proporcionar: "As Histórias do País de Ali-Babá, como qualquer um dos outros volumes da "Biblioteca Infantil", é um livro que há de ficar, sempre lido e relido 
com prazer, não só pelas crianças como também pelos adultos e especialmente pelos velhos." (QUARESMA; QUARESMA; QUARESMA, 1958, n. p.).

Importante observar que tais características presentes na obra vêm em resposta a um contexto produção no qual estava inserida a coleção inicialmente organizada por Figueiredo Pimentel. Efetivamente, o processo de solidificação de uma República ainda jovem requeria uma formação de suas crianças, por meio de uma leitura que, ao mesmo tempo, fosse atrativa e edificante.

Além do prefácio, a edição que consultamos (1958) tem 224 páginas e reúne 20 contos. Embora não aponte a autoria ou origem das narrativas, a folha de rosto (Imagem 4) explica que é um "livro para crianças" e se trata de uma "coleção de histórias maravilhosas, apólogos, lendas e parábolas, colecionadas e relatadas por Deifilia, Rachel e Aurora". (QUARESMA; QUARESMA; QUARESMA, 1958, n. p. [folha de rosto], grifo nosso).

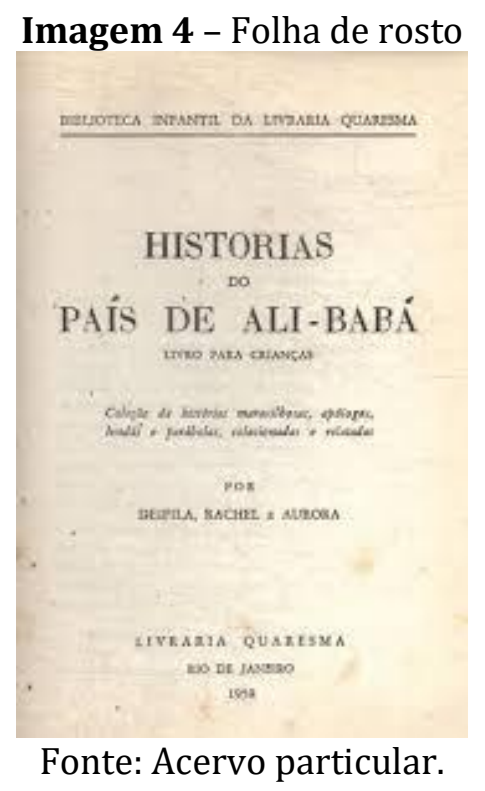

A edição conta ainda com ilustrações. Algumas ocupam quase que completamente a página em que se situam, enquanto outras são menores, localizadas dentro do texto. No total são 34, cujo(s) autor(s) não pudemos identificar visto que não são assinadas, nem há indicação no prefácio da obra.

Imagem 5 - Ilustrações 


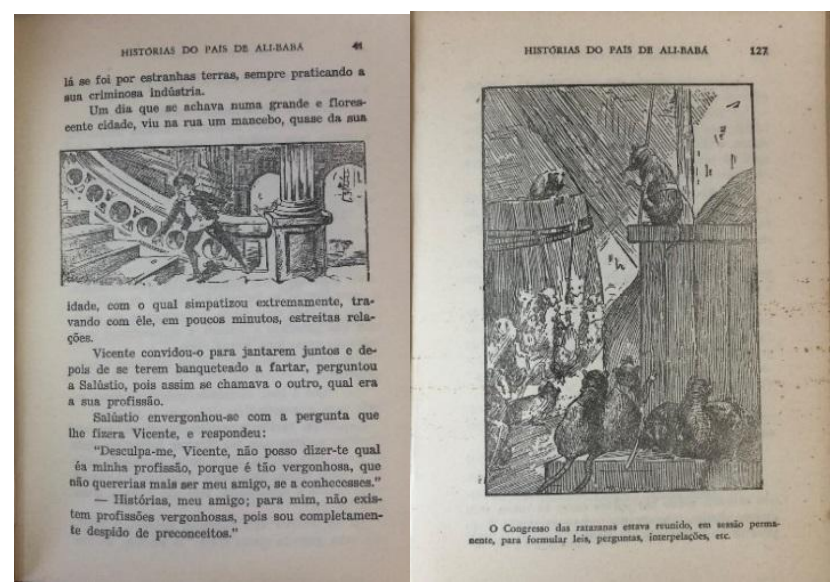

Fonte: Acervo particular.

No corpo das narrativas de Histórias do País de Ali-Babá, de acordo com a classificação de Linden (2011, p. 123), as ilustrações da obra em estudo exercem a função de repetição, significando dizer que

\begin{abstract}
A mensagem veiculada pela instância secundária pode apenas repetir, em outra linguagem, a mensagem veiculada pela instância prioritária. A leitura da segunda mensagem não traz então nenhuma informação suplementar, e o leitor tem a sensação de ler a mesma mensagem de outra maneira. Esse tipo de função induz uma relação de redundância. Longe se ser desinteressante, e para além do conforto de leitura que traz ao jovem leitor, a redundância permite instaurar um ritmo, um hábito de leitura que poderá, por exemplo, dar mais peso a um efeito de contradição.
\end{abstract}

Importante ainda apontar que as ilustrações de página inteira apresentam uma legenda repetindo o trecho da narrativa que ela representa graficamente ou parafraseando a respectiva passagem.

Quanto aos contos da obra, são eles: "A chinelinha de ouro"; "O grão de trigo"; "Os três pedidos"; "Os viajantes misteriosos"; "Branca-flor"; "Vicente, o ladrão"; "A afilhada de Santo Antônio"; "O castigo de um anjo"; "A ambição e o trabalho"; "A cidade da fortuna"; "O concílio das flores"; "O homem da nariganga"; "A guerra das ratazanas"; "Ali-Babá e os quarenta ladrões"; "Bicos de amores"; "D. Mires"; "O isqueiro"; "As aventuras maravilhosas do Mandarim Fum-Hoam"; "Mãe"; "O bobo do rei".

Partindo das tipologias de contos apresentadas por Nelly Novaes Coelho (2000) e Câmara Cascudo (1952), o livro Histórias do País de Ali-Babá é composto por: 
a) contos maravilhosos ou de encantamento: "A chinelinha de ouro"; "Os três pedidos"; "O concílio das flores"; "Bicos de amores"; "D. Mires"; "O isqueiro"; "Ali-Babá e os quarenta ladrões";

b) parábolas ou contos religiosos: "O grão de trigo"; "Os viajantes misteriosos"; "Branca-flor"; "A afilhada de Santo Antônio"; "O castigo de um anjo"; "Mãe";

c) facécia: "Vicente, o ladrão";

d) contos de exemplo: "A ambição e o trabalho"; "A cidade da fortuna"; "O homem da nariganga"; "As aventuras maravilhosas do Mandarim Fum-Hoam"; ${ }^{3}$

e) fábula ou conto de animais: "A guerra das ratazanas"; e

f) conto acumulativo: "O bobo do rei".

Na subseção seguinte, tratamos dos contos "A chinelinha de ouro" e "Castigo de um anjo", apresentando uma breve síntese e sua classificação tomando como aporte teórico Nelly Novaes Coelho (2000) e Câmara Cascudo (1952). Selecionamos para estudo os mencionados contos por representarem os tipos de narrativas com maior recorrência na obra: o conto maravilhoso ou de encantamento; e a parábola ou conto religioso.

\subsection{Os contos "A chinelinha de ouro" e "Castigo de um anjo", de Histórias do País de Ali-Babá}

"A chinelinha de ouro" é um conto maravilhoso (COELHO, 2000; PROPP, 2006) ou de encantamento (CASCUDO, 1952) que narra a história de uma princesa do país dos gelos chamada Lua que um dia perdeu a sua chinelinha de ouro na praia ocasionando a realização de uma profecia existente naquele reino. Segundo essa predição, caso a princesa perdesse a sua chinelinha, o talismã do lugar, este seria arrasado pela fome, por males que acometeriam seu povo, entre outros infortúnios que abateriam o reino.

Embora bravos navegantes tentassem encontrar a chinelinha, para livrar o povo daquele lugar de todos os males presentes, nada adiantou, pois qualquer busca empreendida para o resgate daquele artigo pertencente à princesa não lograva êxito, até que o jovem pescador Mair, perseguindo a chinelinha em alto mar, alcançou o reino que imperava a maldição.

Diante de tanta adversidade encontrada logo na sua chegada, o pescador, de joelhos, clamou pela graça de poder salvar aquele lugar e seus habitantes. Naquele momento apareceu uma boa Fada das Ninfeias, cuja vara tinha em sua ponta a chinelinha da princesa. Tendo isso ocorrido, Mair conseguiu restabelecer o reino, tornou-se rei e casou-se com a princesa, sendo muito amado pelo seu povo. 
Esse conto, como já anunciado, é classificado como maravilhoso, que, segundo Marçal (2009, p. 2), compreende,

[...] uma ausência do princípio de causalidade que outorga aos acontecimentos extraordinários, aos personagens sobrenaturais, aos espaços imaginários e ao tempo fictício uma legitimidade a priori. Admite-se, por antecedência, a existência de leis e regras que fogem à opinião corrente do que deva ser a "normalidade" à qual a natureza e o mundo se submetem.

Para esse tipo de narrativa, Câmara Cascudo (1952, p. 279), que o denomina de conto de encantamento, afirma que estão presentes:

[...] o elemento sobrenatural, o encantamento, dons, amuletos, varinha de condão, virtudes acida da medida humana e natural.

[...]

No conto de encantamento os auxílios são sempre extraterrenos. 0 herói não tem maiores aliados dentro da Humanidade. Os objetos mágicos decidem.

Propp, por sua vez, após um estudo estrutural desse gênero, em Morfologia do conto maravilhoso, propõe a definição de conto maravilhoso nos seguintes termos:

Do ponto de vista morfológico podemos chamar de conto de magia todo desenvolvimento narrativo que, partindo de um dano ( $\underline{\text { A }}$ ou de uma carência (a) e passando por funções intermediárias, termina com o casamento $\left(\underline{\mathrm{W}}^{0}\right)$ ou outras funções utilizadas como desenlace. A função final pode ser recompensa ( $\underline{F})$, a obtenção do objeto procurado ou, de modo geral, a reparação do dano ( $\underline{\mathrm{K}}), \mathrm{o}$ salvamento da perseguição ( $\underline{\text { Rs) }}$ etc (PROPP, 2006, p. 90).

Propp, em sua obra, visa a criar um método para descrever os contos maravilhosos, a fim de encontrar sua gênese. Assim, partindo de uma análise pormenorizada, verificou que essas narrativas ligam-se estreitamente umas às outras, no entanto adverte ser necessário sabermos decompô-las para que seja possível estabelecer uma comparação exata (PROPP, 2006).

Com efeito, seu método parte das funções dos personagens, conceituadas como "[...] procedimento de um personagem, definido do ponto de vista de sua importância para o desenrolar da ação." (PROPP, 2006, p. 22). Isso posto, alicerçado na ação dos personagens, o estudo a que se propõe origina um esquema que possibilita a identificação da origem comum de contos nascido em diferentes lugares e épocas diversas. 
Conforme o estudioso apresenta, as funções dos personagens,' independentemente de quem as pratica e da forma como são exercidas, são constantes no conto maravilhoso. Por outro lado,

[n]o que concerne ao grupamento, antes de tudo é necessário dizer que nem todos os contos maravilhosos apresentam todas as funções. Mas isto não modifica de forma alguma a lei da sequência. A ausência de algumas funções não muda a disposição das demais. (PROPP, 2006, p. 23).

É importante notar que o número das funções dos personagens é limitado a 31 (trinta e uma), e não é necessário que o conto apresente todas as funções. Além disso, contos, apesar de terem origem diversa e de terem surgido em época distinta, podem ser considerados como mesma raiz. Nesse caso, embora apresente variáveis (por exemplo, o afastamento - primeira função do conto maravilhoso pode ser de um membro da família mais velho, mais novo ou ser a morte dos pais), o número de funções é fixo.

Abordando, sucintamente, a estrutura do conto maravilhoso, este costuma partir de uma situação inicial - momento da narrativa em que impera o bem-estar, e os membros da família e o herói são apresentados. Dentro do esquema de Propp, a situação inicial é considerada um elemento morfológico importante, apesar de não ser uma função. Narrado o prelúdio, as funções dos personagens, a seguir elencadas, vão aparecendo: 1) afastamento; 2) proibição; 3) transgressão; 4) interrogatório; 5) informação; 6) ardil; 7) cumplicidade; 8) dano ou carência; 9) mediação, momento de conexão; 10) início da reação; 11) partida; 12) primeira função do doador; 13) reação do herói; 14) fornecimento - recepção do meio mágico; 15) deslocamento no espaço entre dois reinos, viagem com um guia; 16) combate; 17) marca, estigma; 18) vitória; 19) reparação do dano ou carência; 20) regresso; 21) perseguição; 22) salvamento, resgate; 23) chegada incógnito; 24) pretensões infundadas; 25) tarefa difícil; 26) realização; 27) reconhecimento; 28) desmascaramento; 29) transfiguração; 30) castigo, punição; 31) casamento.

No caso do conto ora em estudo, o elemento maravilhoso é configurado pela chinelinha de ouro que age como se tivesse vida própria, tentando escapar de quem a persegue, e pela fada com poderes mágicos.

Sob a perspectiva da análise morfológica de Propp, algumas funções podem ser identificadas:

a) A carência materializada pela perda da chinelinha pela princesa Lua;

b) A proibição advinda da lenda dos sábios em que previa o assolamento do país, caso a princesa perdesse a chinelinha;

c) A transgressão da proibição configurada pela perda da chinelinha;

d) 0 início da reação, quando Mair decide seguir pelo mar a chinelinha de ouro. Mesmo sendo involuntária a reação do herói, uma vez que desconhece a situação do povo do país dos gelos, podemos considerar 
essa ação como reação, visto que, ao chegar no país dos gelos, decide intervir;

e) A partida efetuada pela perseguição que Mair realiza em busca da chinelinha;

f) A primeira função do doador, quando a boa fada das Ninfeias permite a Mair alcançar a chinelinha;

g) 0 fornecimento (recepção do meio mágico) representado pelo êxito de Mair em reaver a chinelinha de ouro (meio mágico).

h) A realização oriunda do reestabelecimento à situação de normalidade do país dos gelos;

i) 0 reconhecimento de Mair em razão da recuperação da chinelinha da princesa e da normalidade local;

j) O casamento de Mair com a princesa Lua no desfecho da história, assumindo a coroa do reinado.

Não obstante a caracterização do conto como maravilhoso, a narrativa tem traços religiosos que podem ser ilustrados, tanto pela passagem de Mair pedindo aos céus condições para salvar o reino da princesa Lua, quanto pelo excerto em que os navegantes suplicam a Deus. Vejamos ambos os trechos: "[...] Então o pescador ajoelhou na barca e com os olhos cheios de lágrimas, ergueu a voz para os espaços, suplicando lhe fosse permitido livrar o país de tamanhos castigos." (QUARESMA; QUARESMA; QUARESMA, 1958, p. 12-13). "Os navegantes que em altos gritos suplicavam de Deus clemência e bonança, e sem forças para guias os navios no remoinho do furacão, os entregam ao acaso e ao destino [...]" (QUARESMA; QUARESMA; QUARESMA, 1958, p. 8).

"Castigo de um anjo" é uma parábola (COELHO, 2000) ou conto religioso (CASCUDO, 1952) que relata a história de um sapateiro de origem muito humilde chamado Nicolau. Esse homem vivia com sua família em uma cabana que lhe fora cedida por um lavrador. Seus recursos eram parcos. Contudo, isso não foi suficiente para deixar de ajudar um rapaz desacordado que encontrou próximo a uma capela. Levado para a casa por Nicolau, o moço, Micael, ficou residindo na casa da família do sapateiro, que o ensinou a mesma função, passando a exercê-la com primor. De acordo com o que dizia ao sapateiro, ele havia aparecido ali, naquela situação, por castigo de Deus. Os anos se passaram, alguns acontecimentos ocorreram e, por fim, Micael revelou que era um anjo, e, após ouvidas as três palavras que havia de ouvir para voltar a sua forma de origem, assumiu a antiga forma: "E o Anjo apareceu na choupana sob a forma celestial, com as asas brancas desdobradas, fulgentes de luz divina. Nicolau e Catarina ajoelharam-se, e Micael voou para o Céu." (QUARESMA; QUARESMA; QUARESMA, 1958, p. 75).

Outras passagens também demonstram o aspecto religioso do conto. Por exemplo, quando a esposa de Nicolau, Catarina, zanga-se por ele ter retornado para casa sem dinheiro e sem as compras, mas acompanhado por um desconhecido, ao que, diante disso, o sapateiro responde: "Não crês em Deus, mulher?" (QUARESMA; QUARESMA; QUARESMA, 1958, p. 64). 
Como se vê, essa narrativa encontrada em Histórias do País de Ali-Babá é uma parábola (ou conto religioso, segundo Cascudo, 1952), considerada por Coelho (2000, p. 168) como "[...] uma narrativa breve de uma situação vivida por seres humanos (ou por humanos e animais), da qual se deduz, por comparação, um ensinamento moral ou espiritual.". De fato, é bem explícito o caráter religioso do conto em tela, bem como a sua prescrição no sentido de mostrar para o bom cristão que não se deve negar uma caridade a quem lhe solicita em um momento de aflição.

parábolas)

Segundo Câmara Cascudo (1952, p. 327), os contos religiosos (ou

Confundem com as Lendas. Essas têm sempre localização geográfica. 0 conto religioso não fixa tempo nem indica zona de influência memorial. Pertence a uma espécie de apologética de espírito popular, com processo especial para a dosagem dos pecados e tabelamento dos méritos.

Através desses contos age a mentalidade coletiva, impondo ao personagem mentalidade, ações, palavras e sentenças de acordo com o sentimento local. Fundem-se, naturalmente, tradições seculares, anteriores ao Cristianismo, nessas estórias que haloam o santoral católico.

A partir de sua leitura, notamos que o conto de Deifilia, Rachel e Aurora segue esse caráter de indeterminação local e temporal, conferindo à narrativa o aspecto apologético apontado por Cascudo. Ademais, soma-se à perspectiva exemplar, conforme o contexto histórico-social dos leitores exigia das obras literárias da época. E, observando a simbologia do conto, notamos a presença de vários elementos representativos do cunho religioso pelo qual o conto é revestido. 0 nome do personagem Micael, por exemplo, remete o leitor ao anjo Miguel, assim como o do personagem Nicolau, na tradição cristã, representa um judeu convertido ao Cristianismo no livro bíblico Atos.

Não apenas os nomes dos personagens trazem uma significação simbólica de ordem religiosa para a narrativa. Símbolos mais explícitos também se fazem presentes, como o anjo, as asas e o céu, apenas para ilustrar. De acordo com Chevalier e Gheerbrant (2008, p. 60), os anjos são "[s]eres intermediários entre Deus e o mundo" e, na literatura, "símbolos de ordem espiritual". As asas, além de comporem a estrutura, digamos que, física dos anjos, simbolizam o "alçar voo" (CHEVALIER; GHEERBRANT, 2008, p. 90), e

[n]a tradição cristã, as asas significam o movimento aéreo, leve, e simbolizam o pneuma, o espírito. Na bíblia, são símbolos constantes da espiritualidade, ou da espiritualização, dos seres que possuem, quer sejam representados por figuras humanas, quer tenham forma animal. Dizem respeito à divindade e a tudo o que dela pode se aproximar, após uma transfiguração; por 
exemplo, os anjos e a alma humana. (CHEVALIER; GHEERBRANT, 2008 , p. 90, grifo no original).

Por fim, o céu constitui-se simbolicamente como "uma manifestação direta da transcendência, do poder, da perenidade, da sacralidade: aquilo que nenhum vivente da terra é capaz de alcançar." (CHEVALIER; GHEERBRANT, 2008, p. 227, grifo no original).

Os aspectos apontados, nesta análise, ilustram o caráter religioso do conto, porém não podemos nos ilidir de notar que o título da narrativa, "Castigo de um anjo", já anuncia, desde a abertura, o cariz não apenas religioso, que paramenta a história, mas também exemplar, visto que, se até anjos são passíveis de serem penalizados, quanto mais crianças desobedientes.

\section{CONCLUSÃO}

Neste trabalho, apresentamos brevemente a obra Histórias do País de AliBabá, lançada pela Livraria Quaresma, entre o final dos anos 30 e início dos 40, do século XX, compondo a coleção Biblioteca Infantil, primeira coleção de obras infantis de autores brasileiros. Como vimos, a obra constitui-se pela reunião de contos de origem popular colecionados pelas escritoras Deifilia da Silva Quaresma, Rachel da Silva Quaresma e Aurora da Silva Quaresma, filhas do livreiro Pedro Quaresma.

Conforme expomos, tanto a obra, quanto as autoras não possuem visibilidade na historiografia da literatura destinada ao público infantil brasileiro, de modo que consideramos pertinente dar um primeiro passo, ainda que incipiente, na busca de informações sobre o objeto que ora tratamos, no intuito de despertarmos o interesse acadêmico e quiçá novas descobertas.

Nesse contexto, é importante lembrar o papel da Livraria Quaresma, com o apoio de Figueiredo Pimentel, na popularização de obras infantis em solo nacional, o que se deu em razão de vários fatores, entre eles: o barateamento de obras literárias e a simplificação da escrita, aproximando as narrativas - que aqui já circulavam, oralmente ou em livros estrangeiros - do mundo infantil. Portanto, oportuno se faz o estudo mais aprofundado de toda coleção, sobretudo, daquelas obras que são superficialmente abordadas nos compêndios de história da nossa literatura infantil, quando o são.

\section{Notas}

${ }^{1}$ Importante notar que, como o falecimento de Figueiredo Pimentel se deu em 1914, as obras O reino das Maravilhas, Contos do País das Fadas, A Árvore de Natal, Histórias Brasileiras, e Histórias do País de Ali-Babá, publicadas posteriormente, não o foram sob a organização do mencionado autor. 
${ }^{2}$ A obra $O$ castigo de um anjo (1897), de Figueiredo Pimentel, é uma tradução de uma versão em francês do conto de Tolstói, também publicado pela Livraria Quaresma. Originalmente essa narrativa fazia parte da Biblioteca Infantil, mais tarde deixou de compor a coleção, motivos os quais desconhecemos. Posteriormente, o conto passou a integrar a obra Histórias do País de Ali-Babá, das irmãs Deifilia, Rachel e Aurora da Silva Quaresma.

${ }^{3}$ Apesar de o título apresentar o termo "aventuras maravilhosas", não há qualquer elemento que possa caracterizar a narrativa como conto maravilhoso.

\section{Referências}

CASCUDO, Câmara. História da literatura brasileira. Vol. VI. Rio de Janeiro: Livraria José Olympio, 1952.

CHEVAlIER, Jean; GHEERBRANT, Alain. Dicionário de símbolos: mitos, sonhos, costumes, gestos, formas, figuras, cores, números. 22. ed. Rio de Janeiro: José Olympio, 2008.

COELHO, Nelly Novaes. Panorama histórico da literatura infantil/juvenil: das origens indoeuropeias ao Brasil contemporâneo. 5. ed. Barueri: Mande, 2010.

JORNAL DAS MOÇAS: Revista Quinzenal Illustrada. Rio de Janeiro. 1914-1919. Disponível em: http://bndigital.bn.gov.br/hemeroteca-digital/. Acesso em: 11 jun. 2020.

LINDER, Sophie Van der. Para ler o livro ilustrado. Trad. Dorothé de Bruchard. São Paulo: Cosac Naify, 2011.

MARÇAL, Marcia Romero. A tensão entre o fantástico e o maravilhoso. Revista FronteiraZ Revista do Programa de Estudos Pós-Graduados em Literatura e Crítica Literária, São Paulo, n. 3 2009. em: http://www4.pucsp.br/revistafronteiraz/numeros_anteriores/n3/download/pdf/tensao.pdf. Acesso em: 18 jan. 2018.

MEDEIROS, Mácio Alves de. Cinge a musa o oráculo da tradição: revelações perenes da narrativa em contos de Perrault. 2010.

O TICO-TICO: Jornal das crianças. Rio de Janeiro. 1905-1961. Disponível em: http://bndigital.bn.gov.br/hemeroteca-digital/. Acesso em: 11 jun. 2020.

PROPP, Vladimir lakovlevitch. Morfologia do conto maravilhoso. Rio de Janeiro: Editora Forense Universitária, 2006.

QUARESMA, Deifilia; QUARESMA, Rachel; QUARESMA, Aurora. Histórias do País de Ali-Babá. Rio de Janeiro: Livraria Quaresma, [193-?]/1958.

SOUSA, Suzana Palermo de. Figueiredo Pimentel, adaptador de contos populares do Brasil para as crianças do século XIX. Linha Mestra, n. 36, p. 992-996, 2018. 


\section{Para citar este artigo}

DUARTE, Christina Rothier. Histórias do país de Ali-Babá, de Deifilia, Rachel e Aurora: um breve estudo sistematizado. Miguilim - Revista Eletrônica do Netlli, Crato, v. 9, n. 3, p. 530-545, set.dez. 2020.

\section{A autora}

Cristina Rothier Duarte é graduada em Letras Licenciatura Plena - Habilitação em Língua Portuguesa pelo Instituto Federal de Educação da Paraíba (2019), bacharela em Direito pela Universidade Federal do Mato Grosso (2000), especialista em Ciências da Linguagem com Ênfase no Ensino da Língua Portuguesa pela Universidade Federal da Paraíba (2018) e em Literatura e Ensino pelo Instituto Federal de Educação do Rio Grande do Norte (2019), tem mestrado em Letras pelo Programa de Pós-Graduação de Letras da Universidade Federal da Paraíba (2019), é doutoranda em Letras pelo mesmo programa e integrante dos grupos de pesquisa: Estágio, Ensino e Formação Docente - Linha Leitura, Literatura infantil e juvenil e Ensino (GEEF-UFPB), Grupo de Estudos em Antropologia Literária (GEAL-UFPB) e Leitura, Ensino de Literatura e Tecnologia na Educação (LEL-IFPB). É professora efetiva de Língua Portuguesa da Rede estadual de ensino da Paraíba. 